\title{
Phase Structures Formed by Photo-Polymerization in Binary Blend of Photocurable/Thermoplastic Polymers
}

\author{
Kazutaka Murata, Hideki EToRI, Toru FuJISAWA, ${ }^{*}$ and Takanori ANAZAWA ${ }^{\dagger}$ \\ Kawamura Institute of Chemical Research, \\ 631 Sakado, Sakura, Chiba 285-0078, Japan \\ * Central Research Laboratories of Dainippon Ink and Chemicals Inc., \\ 631 Sakado, Sakura, Chiba 285-8668, Japan
}

(Received July 29, 1999)

KEY WORDS Polymer Blend/Photo-Polymerization / Phase Decomposition / Interconnecting

Structure

Polymer blends are used for improving polymer materials. ${ }^{1}$ It is of great importance to control phase structure in multicomponent polymer systems. A cocontinuous two-phase structure provides polymers with mechanical properties such as high toughness, large extension and excellent strain recovery..$^{1-5}$ Generally the co-continuous structure develops on spinodal decomposition $^{1}$ induced by temperature jump, ${ }^{1,2}$ chemical reaction, ${ }^{3-12}$ or shear flow ${ }^{13,14}$ at the limited extent near 50 vol\% of composition. A droplet structure is given at asymmetric composition. It was reported recently that a minor polymeric component gives a network-like continuous phase-separated pattern in spite of the asymmetric composition, in the case of binary blend systems having a strong asymmetry in molecular dynamics such as polymer/solvent systems ${ }^{15-17}$ and thermoset/thermoplastic polymers systems. ${ }^{5,6}$ In thermoset/thermoplastic polymers systems, the co-continuous phase structure brought about excellent mechanical properties with small amount of polymer. ${ }^{5}$

Photo-irradiation curing systems have various applications in coatings, inks and adhesion recently due to desirable features such as non-solvent, rapid cure and cold cure. Photo-curing systems have advantages over thermo-curing systems in controlling the phase structures, since the curing temperature and UV light intensity can be easily changeable. However little has been investigated on photo-polymerization curing associated with polymer blends. ${ }^{18,19}$

This paper reports on interconnecting phase structures controlled by photo-polymerization curing in a binary blend of photocurable/thermoplastic polymers, and dependence of phase morphological features on blend compositions, polymerization temperature and UV intensity.

\section{EXPERIMENTAL}

Bisphenol A diacrylate modified ethylene oxide (BPE 4, Daiichi Seiyaku Kougyo, Japan) was used as photocurable monomer. Polysulfone (PSF, Udel P-3703, Amoco) was purified by precipitation in methanol and

\footnotetext{
${ }^{\dagger}$ To whom correspondence should be addressed.
}

used as thermoplastic polymer. 1-hydroxycyclohexylphenyl ketone (Irgacure 184, Ciba Geigy) was used as photo-initiator.

A typical photo-induced phase separation is as follow. PSF ( $1 \mathrm{~g})$ and BPE $4(9 \mathrm{~g})$ including $2 \mathrm{wt} \%$ of Irgacue 184 $(0.18 \mathrm{~g})$ were dissolved in methylene chloride $(60 \mathrm{~g})$ (for $10 \mathrm{wt} \%$ PSF). The solution was cast on a glass slide, and the coating film (ca. $80 \mu \mathrm{m}$ thick) was dried in a vacuum oven at $50^{\circ} \mathrm{C}$ for $1 \mathrm{~h}$. TGA measurement showed residual solvent as below $0.1 \mathrm{wt} \%$ in the coating after dried. In this study, all coatings before the photo-polymerization were transparent viscous fluids over a temperature range of $0-200^{\circ} \mathrm{C}$. The coatings were heated at appropriate temperature on a heat stage and then irradiated with UV light for 2 min using a high-pressure $\mathrm{Hg}$-lamp (Spot Cure 250, Ushio, Japan) at an intensity of ca.10 $\mathrm{mW} \mathrm{cm} \mathrm{c}^{-2}$ at $365 \mathrm{~nm}$. The coatings were further cured by photo-irradiation at $25^{\circ} \mathrm{C}$ (RT) for 1 min using a high power UV light, a $3 \mathrm{~kW}$ metal-halide lamp (UE031, Eye graphics, Japan); light intensity at $365 \mathrm{~nm}$ was $c a .75$ $\mathrm{mW} \mathrm{cm}^{-2}$. Additional photo-irradiation at RT exerted little effect on phase morphology.

Morphological observation was performed by transmission electron microscopy (TEM) using a JEM-200CX (JEOL, Japan). The specimens were microtomed into ultrathin sections of $c a .50 \mathrm{~nm}$ without staining.

\section{RESULTS AND DISCUSSION}

BPE4/PSF blends with the composition of $10 \mathrm{wt} \% \mathrm{PSF}$ were prepared by photo-polymerization at curing temperatures of $30-180^{\circ} \mathrm{C}$. When photo-polymerization temperature was higher than $80^{\circ} \mathrm{C}$, the transparency of the coatings decreased from $90 \%$ to $70-80 \%$ after the photo-irradiation. In contrast, the cured coatings prepared below $70^{\circ} \mathrm{C}$ were transparent. Network-like phaseseparated patterns were clearly observed by TEM for the samples cured above $80^{\circ} \mathrm{C}$; this temperature $\left(80^{\circ} \mathrm{C}\right)$ corresponds to the turbidity temperature of the coating. Figure 1 shows TEM images of a BPE4/PSF blend with composition of $10 \mathrm{wt} \% \mathrm{PSF}$ cured at $120^{\circ} \mathrm{C}$. A minor component (i.e., PSF-rich phase, dark part in Figure 1) appeared as a network-like interconnecting structure in the BPE4-rich matrix. Characteristic length scale, i.e., 


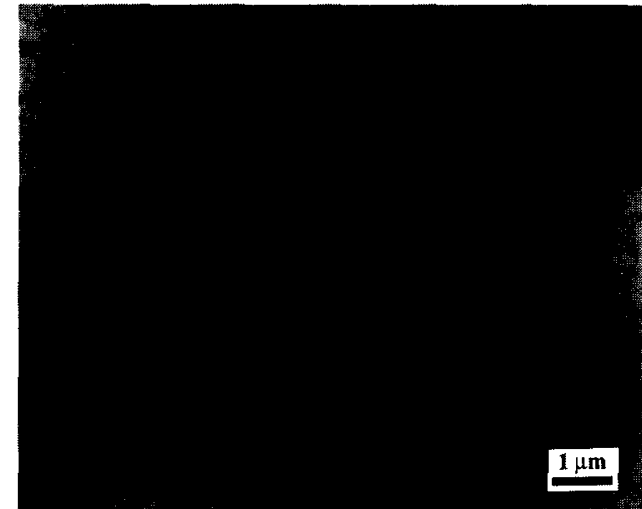

Figure 1. TEM micrograph of BPE4/PSF $(9 / 1, w / w)$ prepared by photo-polymerization at $120^{\circ} \mathrm{C}$.

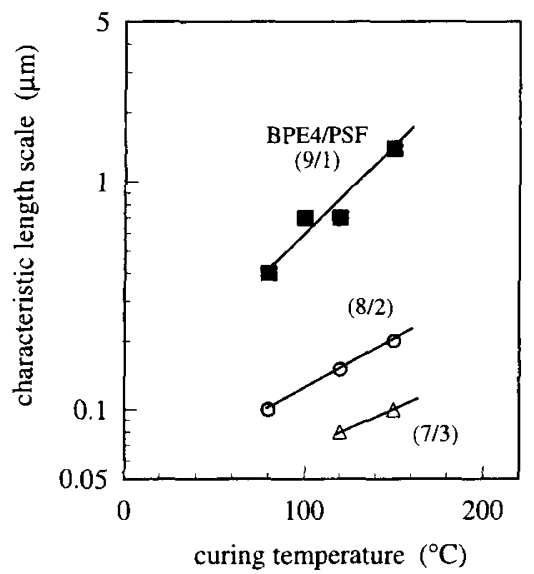

Figure 2. Plots of characteristic length scale versus photo-curing temperature for BPE4/PSF blends. Characteristic length scales were evaluated from TEM micrographs. ( $\square)(\mathrm{BPE} 4 / \mathrm{PSF})=(9 / 1, \mathrm{w} /$ w) ; $(\bigcirc)(8 / 2, \mathrm{w} / \mathrm{w}) ;(\triangle)(7 / 3, \mathrm{w} / \mathrm{w})$.

periodical distance in the network-like pattern, was 0.5 $-0.8 \mu \mathrm{m}$. In TEM images (i.e., patterns in cross section) micro cells of the BPE4-rich part (the light part in Figure 1) were wrapped mostly with the PSF-rich phase continuous three-dimensionally, since the same network-like patterns in the TEM images were observed not to depend on cutting direction of the coating films. Consequently, we consider that there is no isolation of the cells of the BPE4-rich part. This is also supported by the finding that the network-like patterns were partially broken in places in Figure 1 and no powder was given by dipping of coatings in methylene chloride.

Figure 2 shows relationships between curing temperature and characteristic length scale evaluated from the images of TEM. The characteristic length scale depended strongly on curing temperature. At $10 \mathrm{wt} \% \mathrm{PSF}$, the characteristic length scale enlargement was in the order ca. $0.4 \mu \mathrm{m}, c a .0 .6 \mu \mathrm{m}, c a .0 .7 \mu \mathrm{m}$, and $c a .1 .5 \mu \mathrm{m}$, respectively, for increase in curing temperatures, $80^{\circ} \mathrm{C}$, $100^{\circ} \mathrm{C}, 120^{\circ} \mathrm{C}$, and $150^{\circ} \mathrm{C}$. In coatings cured below $70^{\circ} \mathrm{C}$, small network-like patterns were vaguely observed in images of TEM. Phase separation may occur even for coatings cured below $70^{\circ} \mathrm{C}$.

We investigated the phase structures of BPE4/PSF blends at 5-70 wt\% PSF. The network-like phaseseparated patterns appeared from 10-50 wt $\%$ PSF,

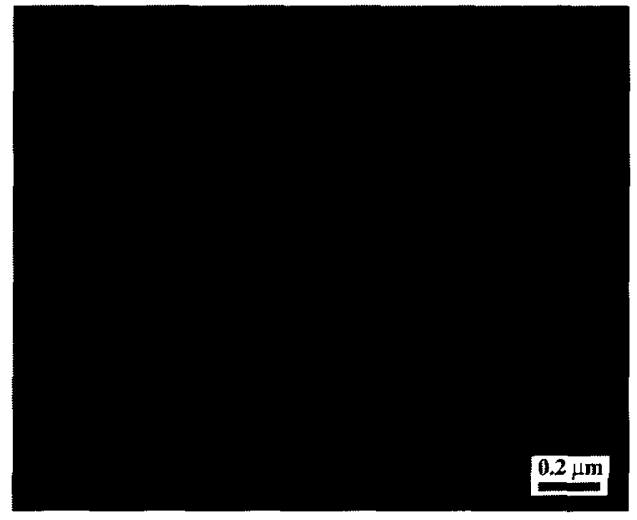

Figure 3. TEM micrograph of BPE4/PSF (1/1, w/w) prepared by photo-polymerization at $180^{\circ} \mathrm{C}$.

while PSF-rich phase provided a shred network-like pattern at $5 \mathrm{wt} \%$ PSF. At $70 \mathrm{wt} \%$ PSF, an island-sea structure appeared. The BPE4-rich phase was distributed as islands in the PSF-rich phase matrix.

The relationships of the characteristic length scales at various compositions with curing temperatures can be seen in Figure 2. The characteristic length scale was drastically reduced from $0.7 \mu \mathrm{m}$ to $0.15 \mu \mathrm{m}$, when PSF composition increased from $10 \mathrm{wt} \%$ to $20 \mathrm{wt} \%$ at $120^{\circ} \mathrm{C}$. Apparently, the characteristic length scale decreased as PSF composition increased. At $50 \mathrm{wt} \%$ PSF, the network-like phase-separated pattern was not clear in TEM images (Figure 3). However, in Figure 3 the characteristic length scale is smaller than $0.1 \mu \mathrm{m}$. The curing temperature at which the phase-separated structure appeared increased with PSF composition at $80^{\circ} \mathrm{C}(10 \mathrm{wt}$ $\%), 120^{\circ} \mathrm{C}(30 \mathrm{wt} \%), 150^{\circ} \mathrm{C}(50 \mathrm{wt} \%)$, and $180^{\circ} \mathrm{C}(70 \mathrm{wt} \%)$. The dependence of curing temperature on PSF composition can be attributed to lower molecular mobility at higher PSF compositions.

The effects of UV intensity on the phase structure were investigated using a high power UV lamp (ca. 75 $\mathrm{mW} \mathrm{cm}{ }^{-2}$ ) which is stronger 7 times than Spot Cure UVlamp (ca. $10 \mathrm{~mW} \mathrm{~cm}^{-2}$ ). A network-like phase-separated pattern also appeared with high-UV intensity. At $10 \mathrm{wt}$ $\% \mathrm{PSF}$, the characteristic length scales at $80^{\circ} \mathrm{C}, 100^{\circ} \mathrm{C}$, $120^{\circ} \mathrm{C}$, and $150^{\circ} \mathrm{C}$ were ca. $0.1 \mu \mathrm{m}, c a .0 .15 \mu \mathrm{m}, c a .0 .2$ $\mu \mathrm{m}$, and $c a .0 .3 \mu \mathrm{m}$, respectively. These values are $c a$. $25 \%$ those with standard UV-intensity. The characteristic length scale became smaller at higher UV intensity. The increase in UV intensity should be related to increase in quench depth in two phase region, ${ }^{1}$ and so the phase-separated structure was fixed at the early stage of phase decomposition.

It is very interesting that the network-like phaseseparated pattern was given with high-UV intensity at $70 \mathrm{wt} \% \mathrm{PSF}$ at which the island-sea structure appeared with lower UV intensity. In the case of the high-UV intensity, the characteristic length scale in the blend was very small $(c a .50-70 \mathrm{~nm})$. It should be noted that network-like phase-separated patterns were also given at curing temperatures above $80^{\circ} \mathrm{C}$ not depending on $\mathrm{UV}$ intensity although characteristic length scale depended strongly on UV-intensity.

In conclusion, the phase structure in a binary blend system of photocurable/thermoplastic polymers was con- 
trolled by photo-polymerization. Network-like phaseseparated patterns were formed by photopolymerization in BPE4/PSF blend over a wide range of compositions of $10-70 \mathrm{wt} \%$ PSF. In particular, the characteristic length scale of a network-like pattern varied from $0.05^{-}-1.5 \mu \mathrm{m}$ at controlled the preparing conditions, and transparent coatings were produced with characteristic length scales below ca. $0.2 \mu \mathrm{m}$.

Acknowledgments. We acknowledge Dr. S. Matsumoto, Dr. N. Hayashi, Mrs. K. Tanaka, and Mrs. R. Fujino of Dainippon Ink and Chemicals Inc. for helpful discussion and TEM observations. We also thank Dr. C. Pac, Dr. R.-H. Jin, and Dr. K. Haraguchi of Kawamura institute of chemical research for helpful discussion and advice.

\section{REFERENCES}

1. L. A. Utracki, "Polymer Alloys and Blends" Oxford University Press, New York, N.Y., 1990.

2. D. Quintens, G. Groeninckx, M. Guest, and L, Aierts, Polym. Eng. Sci., 30, 1474 (1990)
3. K. Yamanaka, Y. Takagi, and T. Inoue, Polymer, 30, 1839 (1989).

4. H. Fujiwara, B. S. Kim, and T. Inoue, Polym. Eng. Sci., 36, $1541(1996)$

5. K. Yamanaka and T. Inoue, Polymer, 30, 662 (1989).

6. K. Yamanaka and T. Inoue, J. Mater. Sci., 25, 241 (1990).

7. B. S. Kim, T. Chiba, and T. Inoue, Polymer, 36, 43 (1995).

8. J.-P. Chen and Y.-D. Lee, Polymer, 36, 55 (1995).

9. T. Kyu and J.-H. Lee, Phys. Rev. Lett., 76, 3746 (1996).

10. W. Chen, X. Li, T. Dong, and M. Jiang, Macromol. Chem. Phys., 199, 327 (1998).

11. W. Chen, S. Kabayashi, T. Inoue, and T. Ougizawa, Polymer, 35, 4015 (1994).

12. W. Chen, X. Li, and M. Jiang, Macromol. Chem. Phys., 199, 319 (1998).

13. Hindawi, J. S. Higgins, A. F. Galambos, and R. A. Weiss, Macromolecules, 23, 670 (1990).

14. M. Okamoto, K. Shiomi, and T. Inoue, Polymer, 36, 87 (1995).

15. Y. Fukahori, N. Mashita, Y. Wakana, and T. Utsunomiya, Polym. Prepr. Jpn., 47, 2692 (1998).

16. H. Tanaka, Macromolecules, 25, 6377 (1992).

17. H. Tanaka, Phys. Rev. Lett., 76, 787 (1996).

18. Q. T-Cong, T. Nagaki, T. Nakagawa, O. Yano, and T. Soen, Macromolecules, 22, 2720 (1989).

19. L. H. Sperling and D. W. Friedman, J. Polym. Sci., Part-II, 7, 425 (1969). 